\title{
Imaging Flow Cytometry Protocols for Examining Phagocytosis of Microplastics and Bioparticles by Immune Cells of Aquatic Animals
}

\author{
Youngjin Park ${ }^{1}$, Isabel S. Abihssira-García ${ }^{1}$, Sebastian Thalmann ${ }^{2}$, Geert F. Wiegertjes ${ }^{3}$, \\ Daniel R. Barreda ${ }^{4}$, Pål A. Olsvik ${ }^{1}$ and Viswanath Kiron ${ }^{1 *}$ \\ ${ }^{1}$ Faculty of Biosciences and Aquaculture, Nord University, Bodø, Norway, ${ }^{2}$ Luminex B.V., 's-Hertogenbosch, Netherlands, \\ ${ }^{3}$ Aquaculture and Fisheries Group, Wageningen University \& Research, Wageningen, Netherlands, ${ }^{4}$ Department of Biological \\ Sciences, University of Alberta, Edmonton, AB, Canada
}

Imaging flow cytometry (IFC) is a powerful tool which combines flow cytometry with digital microscopy to generate quantitative high-throughput imaging data. Despite various advantages of IFC over standard flow cytometry, widespread adoption of this technology for studies in aquatic sciences is limited, probably due to the relatively high equipment cost, complexity of image analysis-based data interpretation and lack of core facilities with trained personnel. Here, we describe the application of IFC to examine phagocytosis of particles including microplastics by cells from aquatic animals. For this purpose, we studied (1) live/dead cell assays and identification of cell types, (2) phagocytosis of degradable and non-degradable particles by Atlantic salmon head kidney cells and (3) the effect of incubation temperature on phagocytosis of degradable particles in three aquatic animals-Atlantic salmon, Nile tilapia, and blue mussel. The usefulness of the developed method was assessed by evaluating the effect of incubation temperature on phagocytosis. Our studies demonstrate that IFC provides significant benefits over standard flow cytometry in phagocytosis measurement by allowing integration of morphometric parameters, especially while identifying cell populations and distinguishing between different types of fluorescent particles and detecting their localization.

Keywords: ImageStream $\AA^{\mathrm{x}}$, IFC, Atlantic salmon, Nile tilapia, blue mussel, phagocytosis

\section{INTRODUCTION}

Flow cytometry (FC) is widely employed for studying mammalian cells in particular and detecting biomarkers in clinical studies. FC systems quantify cell data within seconds and can provide information on cell phenotypes and functions. However, conventional FC is not designed to measure morphological and spatial information of single cells, and the technology is not able to efficiently detect dim and small particles $(<300 \mathrm{~nm})(1)$ as well as to distinguish aggregates of these small particles. Furthermore, although conventional FC can measure intra- and extracellular marker expressions, it does not provide information on marker localization. Another obstacle connected to conventional FC is auto-fluorescence. While the system cannot always precisely distinguish between false-positive and false-negative events (2), fine-tuning of instrument settings and protocol optimization can minimize the problem (3). Nevertheless, cell phenotype identification and functional analyses using conventional FC cannot be entirely objective as the equipment lacks image-capturing features. To overcome inaccuracies in acquiring cell data, 
quantitative studies preferably rely on both conventional FC and fluorescent cell imaging.

Imaging flow cytometry (IFC), also called multispectral imaging flow cytometry, is a powerful tool that enables us to collect information from single cells, including those from fluorescent images. Major advantages of IFC are (1) high fluorescence sensitivity, (2) high image resolution capability, (3) high speed processing, (4) ability to analyse changes in cell or nuclear morphology, (5) rare cell detection ability, and (6) capacity to understand cell-cell interaction (2). Certain disciplines of biology, namely hematology (4), immunology (5), cell biology (6), and microbiology (7) have already benefited from IFC. However, application of IFC is still in its infancy when it comes to studies in aquatic sciences.

Researchers have reported IFC-based analyses of fish cells, using nucleus staining to understand cell morphology and employing fluorescent particles to determine phagocytic activity in goldfish $(8,9)$. Different particles such as fluorescent latex beads (10), zymosan-APC (8), and nanoparticles (11) have been used to analyse phagocytosis using IFC. These methods can be further optimized, depending on the characteristics of the particles, e.g., latex beads that are not degraded vis-à-vis $\mathrm{pHrodo}^{\mathrm{TM}}$ BioParticles ${ }^{\circledR}$ that emit fluorescent light upon acidification following ingestion by the target cells (10). Researchers have also improved the protocol for measuring particles' intensity in IFC (12). Overall, these studies provide the first information on the use of IFC to identify different cells and understand cell functions such as phagocytosis and the localization of markers of interest in cells from aquatic animals.

Though previous studies on aquatic animals have reported phagocytosis, here we present (1) basic, but optimized protocols for live/dead cell assay and identification of cell types (2), an improved protocol for examining phagocytosis of non-degradable (microplastic) and degradable (bioparticles) particles by immune cell types of fish, and (3) an optimized phagocytosis assay using cells harvested from three very different aquatic animals: cold water-adapted carnivorous marine fish (Atlantic salmon, Salmo salar), warm water-adapted omnivorous, freshwater fish (Nile tilapia, Oreochromis niloticus) and a cold water-adapted detritivorous/planktivorous marine mollusc (blue mussel, Mytilus edulis). Effect of incubation temperature was studied to verify the sensitivity and usefulness of the optimized phagocytosis assay.

\section{METHODS}

\section{Ethics Statement}

The studies were approved (Atlantic salmon: FOTS ID 10050, Nile tilapia: FOTS ID 1042) by the National Animal Research Authority in Norway (Mattilsynet). The fish rearing and handling procedures were according to the approved protocols of FDU.

\section{Animals}

Atlantic salmon (S. salar) in the weight range $700-900 \mathrm{~g}$ were used in this experiment. They were purchased from a commercial producer (Sundsfjord Smolt, Nygårdsjøen, Norway) and maintained at the Research Station of Nord University,
Bodø, Norway. Fish were fed a commercial feed (Ewos AS, Bergen, Norway) and reared in a flow-through sea water system (temperature: $7-8^{\circ} \mathrm{C}$, dissolved oxygen saturation: $87-92 \%, 24-\mathrm{h}$ light cycle).

Nile tilapia (O. niloticus, 400-600 g) were bred and reared at the Research Station of Nord University in a freshwater recirculating aquaculture system (temperature: $28^{\circ} \mathrm{C}, \mathrm{pH}$ : 7.6, dissolved oxygen saturation: $80 \%$ in outlet and $115 \%$ in inlet, $11 \mathrm{~h}$ dark/13 h light cycle). The fish were fed commercial feeds (Skretting, Stavanger, Norway) during the rearing period.

Adult blue mussels ( $M$. edulis) were collected from a beach along the Saltenfjorden, Bodø, Norway $\left(67^{\circ} 12^{\prime} 01^{\prime \prime}\right.$ N $14^{\circ} 37^{\prime} 56^{\prime \prime}$ E) and transported to the Research Station, Nord University. Prior to isolation of hemocytes, they were kept for 2 days in running seawater at $7-8^{\circ} \mathrm{C}$.

\section{Cell Isolation}

Cells from salmon and tilapia head kidney (HK) were grown in Leibovitz's L-15 Medium (L-15; Sigma-Aldrich, Oslo, Norway), supplemented with $100 \mu \mathrm{g} / \mathrm{mL}$ gentamicin sulfate (Sigma), $2 \mathrm{mM}$ L-glutamine (Sigma) and $15 \mathrm{mM} \mathrm{HEPES} \mathrm{(Sigma).} \mathrm{Osmolality}$ of medium was adjusted by adding a solution consisting of $5 \%$ (v/v) $0.41 \mathrm{M} \mathrm{NaCl}, 0.33 \mathrm{M} \mathrm{NaHCO}_{3}$, and 0.66 (w/v) D-glucose. Cell culture media were adjusted to 380 mOsm for salmon and $320 \mathrm{mOsm}$ for tilapia. To culture the mussel hemocytes, filtered (through a $0.2 \mu \mathrm{m}$ mesh) sea water was used as the medium.

Head kidney from salmon $(n=6)$ were sampled after the fish were killed with an overdose of MS-222 (Tricaine methane sulphonate; Argent Chemical Laboratories, Redmond, USA; 80 $\mathrm{mg} / \mathrm{L})$. Thereafter, the HK cells were isolated as described previously (13) with minor modifications. Briefly, HK was dissected out, and the tissues were transferred to $15 \mathrm{~mL}$ centrifuge tubes to make a total volume of $4 \mathrm{~mL}$ in ice-cold $\mathrm{L}-15+$ (L15 medium with $50 \mathrm{U} / \mathrm{mL}$ penicillin, $50 \mu \mathrm{g} / \mathrm{mL}$ streptomycin, $2 \%$ fetal bovine serum (FBS) and $10 \mathrm{U} / \mathrm{mL}$ heparin). The tissue was placed on a sterile $100 \mu \mathrm{M}$ cell strainer (Falcon) and the cells were disrupted with the help of a syringe plunger. The harvested cells were washed twice in ice-cold L-15+. The cell suspension from salmon HK was then layered on $40 / 60 \%$ Percoll (Sigma) to separate HK leukocytes for magnetic-activated cell sorting (MACS) or layered on 34/51\% Percoll to separate monocytes/macrophages for subsequent phagocytosis assays. After centrifugation $\left(500 \times \mathrm{g}, 30 \mathrm{~min}, 4^{\circ} \mathrm{C}\right)$, the cells at the interface between the two Percoll gradients were collected and washed twice with ice-cold L-15-FBS free (L-15 medium with $50 \mathrm{U} / \mathrm{mL}$ penicillin, $50 \mu \mathrm{g} / \mathrm{mL}$ streptomycin) by centrifugation $\left(500 \times \mathrm{g}, 5 \mathrm{~min}, 4^{\circ} \mathrm{C}\right)$. Cells were then kept in $\mathrm{L}-15+$. HK phagocytic cells that were separated based on 34/51\% Percoll gradient, were allowed to adhere on a petri dish for 3 days at $12^{\circ} \mathrm{C}$. After removing the supernatant containing non-adherent cells, the petri dish with the adherent cells was placed on ice for $10 \mathrm{~min}$, and the cells were collected by washing three times with $1.5 \mathrm{~mL}$ ice-cold PBS supplemented with $5 \mathrm{mM}$ EDTA. Next, these collected cells were centrifuged $\left(500 \times \mathrm{g}, 5 \mathrm{~min}, 4^{\circ} \mathrm{C}\right)$ and used for further analyses.

Head kidney from tilapia $(n=6)$ were collected after killing the fish with an overdose of clove oil (Sigma Aldrich, St. Louis, 
MO, USA), and cells were harvested as described previously $(14,15)$, with minor modifications. Briefly, the HK tissues were transferred to $15 \mathrm{~mL}$ centrifuge tubes to make a total volume of $4 \mathrm{~mL}$ in ice-cold L-15+. The cells were harvested from the HK and washed twice as described for salmon. The cell suspension was layered on $34 / 51 \%$ Percoll to separate phagocytic cells, and then after centrifugation, cells at the interface were collected and washed twice in L-15-FBS free. The cells in the suspension were allowed to adhere on a petri dish containing L-15+ for 3 days at $25^{\circ} \mathrm{C}$. After removing the supernatant containing non-adherent cells, the petri dish with the adherent cells was placed on ice for $10 \mathrm{~min}$, and the cells were collected by washing three times with $1.5 \mathrm{~mL}$ ice-cold PBS supplemented with $5 \mathrm{mM}$ EDTA. Next, the collected cells were centrifuged $\left(500 \times \mathrm{g}, 5 \mathrm{~min}, 4^{\circ} \mathrm{C}\right)$ and used for further analyses.

In the fish experiments, the cells were counted using a portable cell counter (Scepter ${ }^{\mathrm{TM}} 2.0$ cell counter, EMD Millipore, Darmstadt, Germany).

Hemocytes from adult mussels $(n=6)$ were isolated as described previously (16) with minor modifications. Briefly, hemolymph was drawn from the posterior adductor muscle using a $2 \mathrm{~mL}$ syringe equipped with a $23 \mathrm{G}$-needle. The hemocytes from each mussel were counted using a Neubauer chamber, and $0.2 \times$ $10^{6}$ cells per sample were collected and re-suspended in $1 \mathrm{~mL}$ of filtered sea water to avoid formation of clumps.

\section{Magnetic-Activated Cell Sorting (MACS) of Salmon IgM ${ }^{+}$Cells}

The isolated salmon HK leukocytes $\left(2 \times 10^{6}\right.$ cells $)$ were incubated with mouse anti-trout/salmon $\operatorname{IgM}(6.06 \mu \mathrm{g} / \mathrm{mL}$; Aquatic Diagnostics Ltd, Sterling, UK) for $60 \mathrm{~min}$ at $4^{\circ} \mathrm{C}$. After two washes with $\mathrm{L}-15+$, the cells were incubated for $15 \mathrm{~min}$ at $4^{\circ} \mathrm{C}$ in a cocktail with a total volume of $100 \mu \mathrm{L}$, which contained $\mathrm{L}-15+, 1 \mu \mathrm{L}$ of goat anti-mouse IgG-FITC $(0.75 \mathrm{mg} / \mathrm{mL}$; Thermo Fisher Scientific, Oslo, Norway) and $40 \mu \mathrm{L}$ of goat anti-mouse IgG microbeads as per the instructions of the manufacturer (Miltenyi Biotec, Bergisch Gladbach, Germany). First, MACS LD columns (Miltenyi Biotec) that were placed in a magnetic separator of the multistand were washed using L-15+. The cell suspension was then transferred into the LD column. Following cell sorting, the positive cells were harvested and re-suspended in $\mathrm{L}-15+$.

\section{Live/Dead Cell Assay}

In the studies on cells from salmon and tilapia, aliquots containing $1 \times 10^{6}$ cells in $50 \mu \mathrm{L}$ PBS were transferred to $1.5 \mathrm{~mL}$ microcentrifuge tubes. Then $1 \mu \mathrm{L}$ of propidium iodide (PI; 1 $\mathrm{mg} / \mathrm{mL}$, Sigma) was added to each sample to detect the dead cells in the cell suspension. In the case of mussel, aliquots containing $0.2 \times 10^{6}$ cells in $50 \mu \mathrm{L}$ filtered sea water were transferred to $1.5 \mathrm{~mL}$ microcentrifuge tubes, and then $1 \mu \mathrm{L}$ of DRAQ5 ${ }^{\mathrm{TM}}$ (25 mM, Thermo Fisher Scientific) was added to each sample to detect the dead cells in the cell suspension. The tubes were gently mixed before the samples were run through the ImageStream ${ }^{\circledR} \mathrm{X}$ Mk II Imaging Flow Cytometer (Luminex Corporation, Austin, TX, USA). Cell analyses were performed on 10,000 cells acquired at a rate of 300 objects/second at low speed and a magnification of
$40 \times$. Dead cells were estimated as the percent of cells positive for either PI or DRAQ5 ${ }^{\mathrm{TM}}$ (red fluorescent cells). After excluding the dead cells, viable cells were analyzed to generate brightfield (BF) area (size) vs. side scatter (SSC) intensity (complexity) dot plots. Instrument settings were kept identical throughout the study.

\section{Phagocytosis Assay}

In the first phagocytosis experiment, phagocytic cells from salmon HK were employed to study the uptake of two types of particles; non-degradable fluorescent polystyrene microplastic beads ( $2.1 \mu \mathrm{m}$; Magsphere Inc., California, USA) and degradable fluorescent bio-particles ( $>0.2 \mu \mathrm{m}$; pHrodo $^{\mathrm{TM}}$ Red Escherichia coli Bioparticles, Thermo Fisher Scientific). In the second experiment, we used degradable fluorescent bio-particles only; to determine phagocytic ability and capacity of the cells from salmon, tilapia and mussel at two different incubation temperatures. Phagocytic ability was measured as the percent of phagocytic cells among the total macrophage-like cells or hemocytes. On the other hand, phagocytic capacity was measured as the mean number of particles per phagocytic cell. Phagocytic index (PI) or phagocytic activity was determined employing the equation $(17,18)$ :

Phagocytic index $(\mathrm{PI})=[\%$ phagocytic cells containing at least one particle] $\times$ [mean particle count per phagocytic cell].

Briefly, fluorescent bio-particles were added at a cell:particle ratio of 1:5 per sample, both in the case of $\mathrm{HK}$ macrophages $\left(0.5 \times 10^{6}\right.$ cells $)$ and hemocytes $\left(0.2 \times 10^{6}\right.$ cells $)$. Cells suspensions and bio-particles were mixed and incubated for $2 \mathrm{~h}$ at different temperatures. Following incubation, cell suspensions were washed twice with $500 \mu \mathrm{L}$ L-15+ by centrifugation $(500 \times$ $\mathrm{g}, 5 \mathrm{~min}, 4^{\circ} \mathrm{C}$ ). The supernatant was discarded, and the resulting cell pellets were re-suspended in $50 \mu \mathrm{L}$ PBS. The cell samples were run in an imaging flow cytometer (Luminex), equipped with a $10 \mathrm{~mW} 488 \mathrm{~nm}$ argon-ion laser, to detect the bio-particle fluorescence (577/35 nm bandpass; Channel 3). Thereafter, the images were analyzed using IDEAS 6.1.822.0 software (Luminex).

\section{Data and Statistical Analyses}

Statistical analysis was performed in RStudio version 1.1.463. Normality of the data was tested by Shapiro-Wilk Test, and the assumption of equal variance was checked by Bartlett's Test. Comparisons between the two groups were performed using unpaired Student's $t$-test. Statistically significant differences $(p<$ 0.05 ) are reported for the phagocytosis data.

\section{RESULTS}

\section{Live/Dead Cells and Leukocyte Populations From Salmon Head Kidney}

To determine single cell area and to identify cell populations, we employed a basic gating strategy using the Brightfield Gradient Root Mean Square (RMS) feature of the imaging flow cytometer (see Figure 1). This strategy helped us to select the cells in best focus, i.e., this allowed us to obtain high quality images with RMS values $>50$ (Figure 1A). Next, we separated single cells from others (debris, doublets and aggregates; Figure 1B). Dead cells were excluded based on 


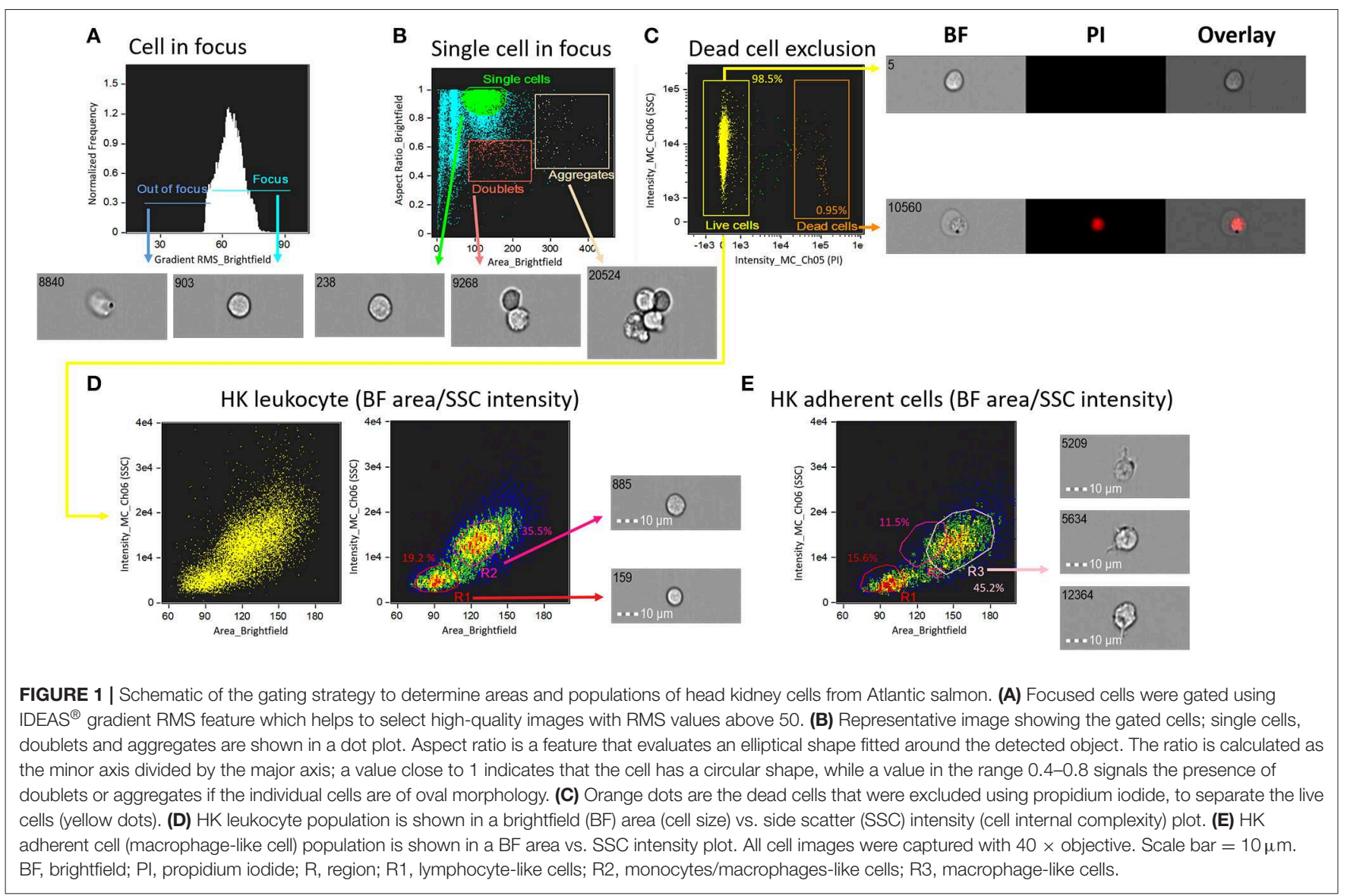

positivity for PI (Figure 1C). The percentage of live cells were $98.5 \%$. The brightfield (BF) area and side scatter (SSC) intensity of the live, single cells were assessed. We prepared a $\mathrm{BF}$ area vs. SSC intensity dot plot to show the salmon HK leukocyte populations (Figure 1D). Cells with smaller size (low $\mathrm{BF}$ area) and low SSC intensity were possibly lymphocyte-like cells (19.2\%; R1 in Figure 1D) while those with larger size (BF area) and higher SSC intensity compared to lymphocytelike cells were considered as monocytes/macrophages $(35.5 \%$; R2 in Figure 1D). Figure 1E shows salmon $\mathrm{HK}$ adherent cell populations in a BF area vs. SSC intensity dot plot; here, R3 is probably $\mathrm{HK}$ macrophage-like cells (45.2\%). We conclude that using IFC, dead cells can be excluded, and different single cell populations can be better detected than in conventional FC.

\section{Salmon Head Kidney lgM+ Lymphocyte Identification}

Salmon head kidney $\operatorname{IgM}^{+}$lymphocytes separated using MACS were used to ascertain their localization in a BF area vs. SSC intensity dot plot (Figure 2). For this purpose, cells were extracellularly stained with IgM-FITC, which enabled us to identify areas of negatively- and positively-stained B lymphocyte populations. Before MACS (Figure 2A), all cells were located in the $\operatorname{IgM}^{-}$area (right panel Figure 2A). After staining with
IgM-FITC and performing MACS (Figure 2B), most cells were located in the $\operatorname{IgM}^{+}$area (89.8\%; right panel Figure $2 \mathbf{B}$ ). These data confirmed that the $\operatorname{IgM}^{+}$cells matched the location of the lymphocyte-like cells (R1 population in Figure 1D). Thus, we confirmed the localization of salmon $\operatorname{IgM}^{+}$cells using IFC.

\section{Examining Phagocytosis Using Non-degradable Fluorescent Microplastic Beads}

To determine the phagocytosis of microplastics by salmon HK cells, first, we plotted histograms of fluorescence intensity of nondegradable fluorescent polystyrene microplastic beads in live cells (Figure 3A). Because all the polystyrene beads were of similar size, we assumed that fluorescence intensity is proportional to the number of beads taken up by each phagocytic cell. Using IFC, we could exclude auto-fluorescence and could gate images with more pixels and higher intensity (phagocytic images with pixel value $>$ 30 were considered to be of high quality) (Figure 3B). Caution was taken to exclude aggregates; addition of many microplastic beads can cause bead aggregation, leading to false identification of aggregates as phagocytic cells, especially in conventional FC. Next, we gated phagocytic cells that engulfed microplastic beads using an internalization score (Figure 3C). This score is the ratio of the particle intensity inside a cell to the intensity of the whole cell, and it is calculated after masking (which selects pixels 

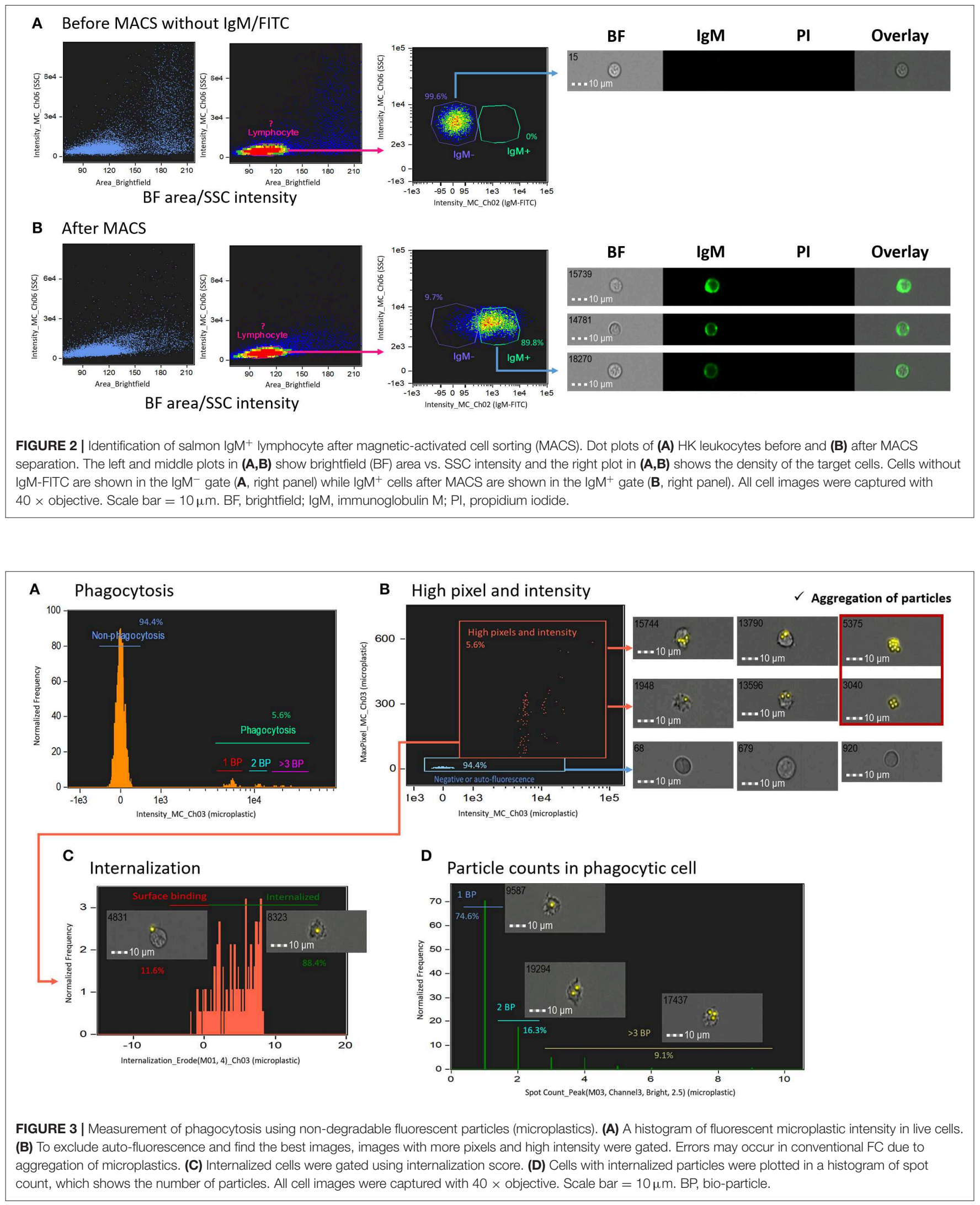
within an image based on their intensity and localization) with the following mask function [Erode (M01, 4)_Ch03]. The ratio indicated the proximity of microplastic to the center of the cell; cells with a score of $>0.3$ were considered to have internalized particles and those with a score of $<0.3$ were considered to have surface-bound particles (11). Finally, only cells with internalized particles were presented in a histogram of spot count feature, which is an ideal approach to quantify the masked spots in the cell (Figure 3D). Overall, IFC can be applied for detecting non-degradable microplastic beads inside the phagocytic cells and quantifying the number of beads. In addition, salmon HK phagocytic cells could recognize microplastics as foreign bodies although we observed only few phagocytosed particles.

\section{Examining Phagocytosis Using Degradable Fluorescent Bio-particles}

To determine phagocytosis of degradable bio-particles by salmon HK cells compared with non-degradable microplastics, first, we plotted histograms of fluorescence intensity of degradable bioparticles (Figure 4A). In comparison to the histogram of the nondegradable microplastic beads described above (Figure 3), it was more difficult to distinguish the number of bio-particles in this histogram. To exclude auto-fluorescence and obtain high-quality images, we adopted a gating strategy based on high pixel (pixel value $>30$ ) and intensity of images (Figure 4B). We created two gates, one to include particles with high pixel and high intensity and the other one with negative or auto-fluorescence (histogram in Figure 4B). From the histogram, it is clear that overlapping particle intensity (orange) and auto-fluorescence (blue) curves can cause detection errors. Cells that had engulfed the bio-particles were gated using the internalization score as described in the previous section (Figure 4C). Finally, only cells with internalized particles are presented in a histogram of particle intensity to understand the number of particles in the phagocytic cells (Figure 4D). We found that to quantify the number of degradable particles, particle intensity-based protocol is a better strategy compared to the method employing spot count feature.

\section{Optimizing IFC-Based Method for Phagocytosis Assay}

To verify the validity of our IFC-based method, we used degradable fluorescent bio-particles from E. coli to assess the effect of incubation temperature on the phagocytic activity and capacity of phagocytic cells from three aquatic animals. The phagocytic ability of $\mathrm{HK}$ phagocytic cells from salmon (Figure 5A) and tilapia (Figure 6A) incubated at 12 and $25^{\circ} \mathrm{C}$, respectively, was significantly higher compared to cells incubated at $4{ }^{\circ} \mathrm{C}$, but temperature did not significantly affect the phagocytic ability of hemocytes from blue mussel (Figure 7A). In contrast, the phagocytic capacity of none of the aquatic species tested

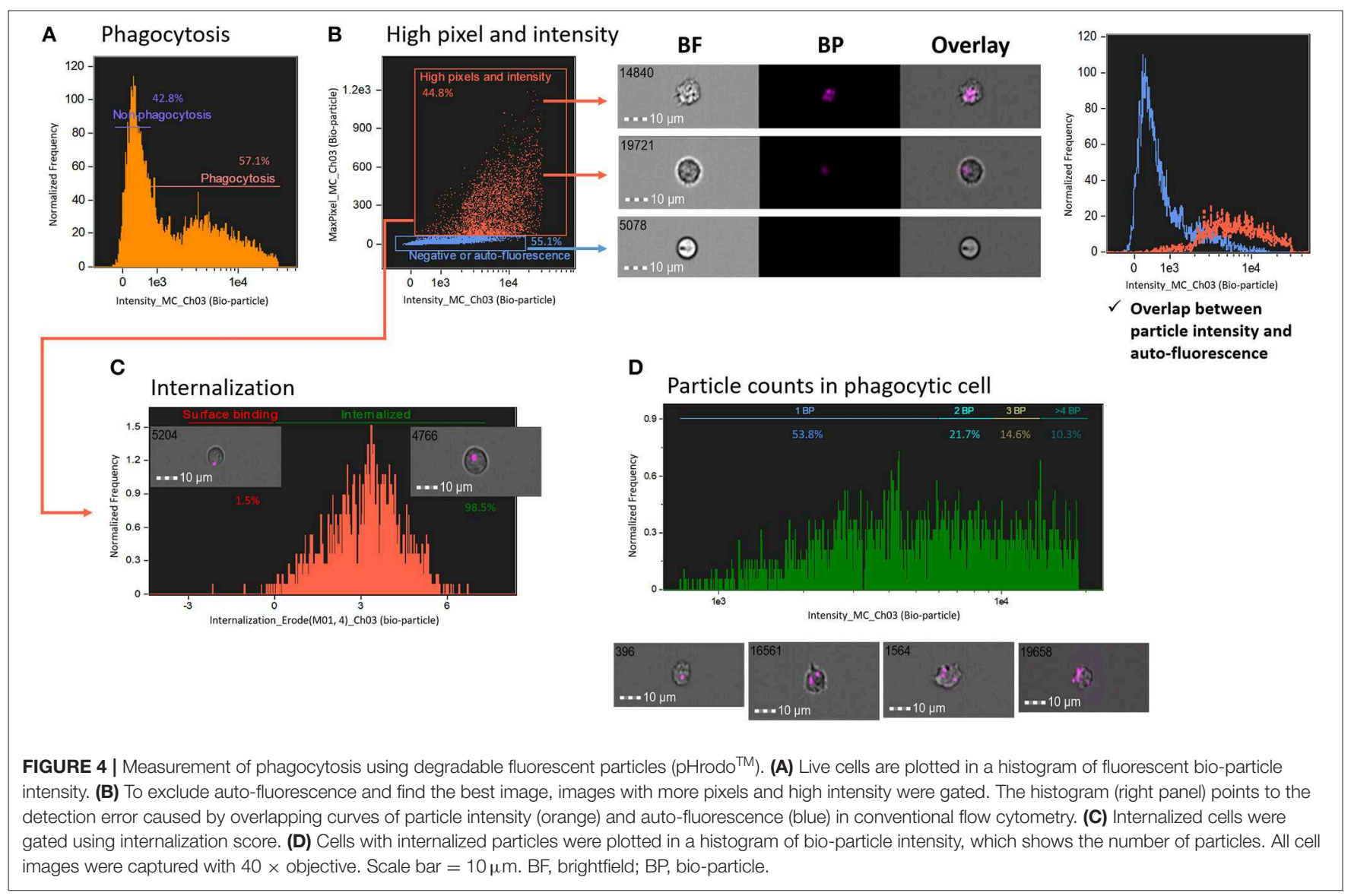




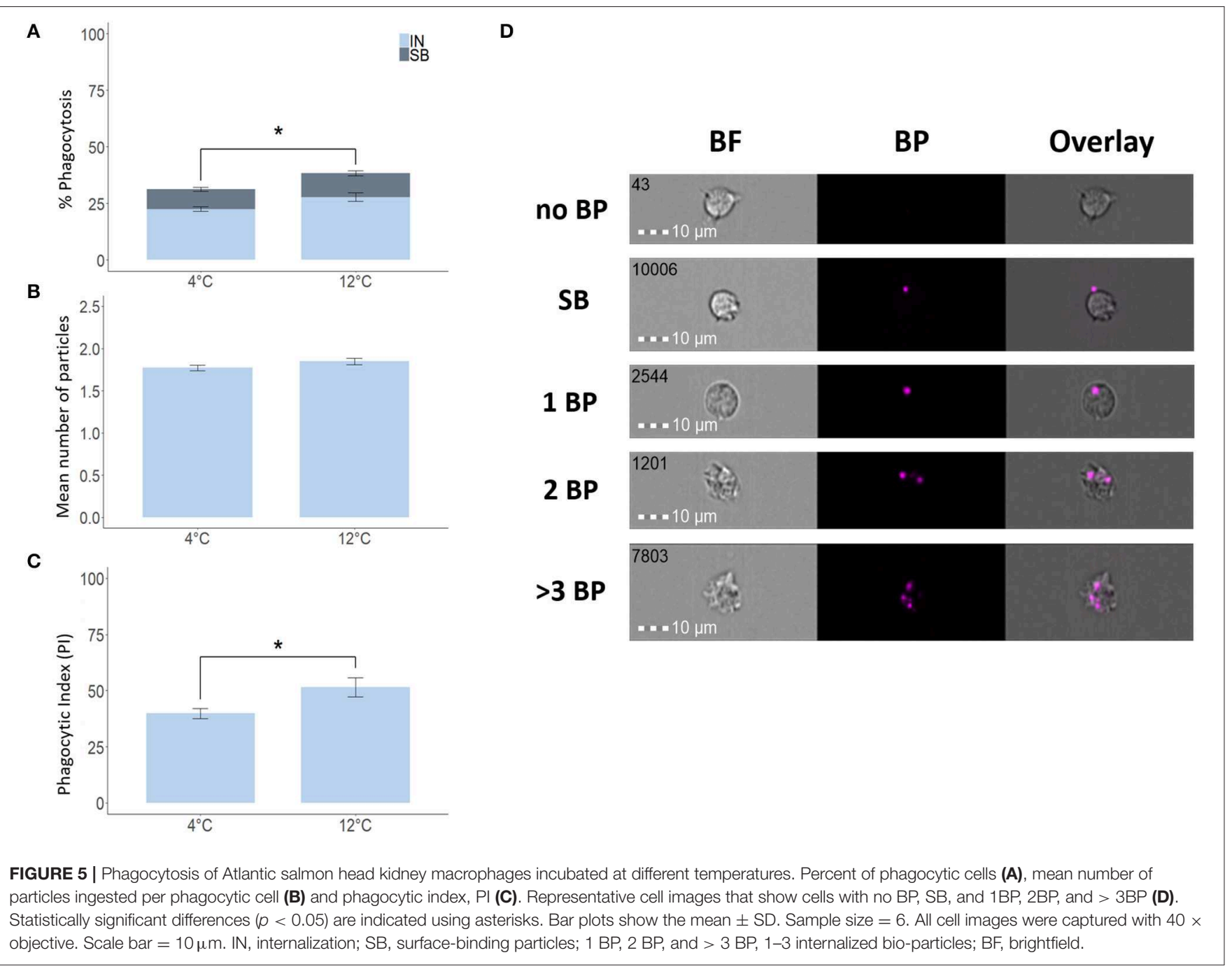

was significantly affected by temperature (Figures 5B,D, 6B,D, 7B,D). The phagocytic index of only the salmon cells incubated at $12^{\circ} \mathrm{C}$ was significantly higher compared to cells incubated at $4^{\circ} \mathrm{C}$ (Figure 5C). This temperature effect could not be detected for the phagocytic index of tilapia HK cells (Figure 6C) and blue mussel hemocytes (Figure 7C) although the cells were incubated at higher values, i.e., 12 and $25^{\circ} \mathrm{C}$, respectively. The optimized method for phagocytosis assay was well-applied to phagocytic cells from three aquatic animals. The results showed that unlike that of phagocytic cells from fishes, phagocytosis of the cells from mussel was not significantly affected by incubation temperature.

\section{DISCUSSION}

The major advantage of imaging flow cytometry (IFC) over conventional flow cytometry (FC) is its ability to distinguish between false-positive and false-negative events by considering additional features of the captured cellular images (2). The two systems share the basic principle (19). Although IFC has been widely adopted to study mammalian cell types, it is not yet commonly employed to investigate other organisms, including aquatic animals. There is a paucity of appropriate tools such as cell-specific markers, which hampers the wider adoption of new technologies like IFC. Furthermore, the associated protocols require thorough refining before IFC can be used to study cell types from aquatic animals. For example, as the weak and small fluorescence cannot be detected by the system, we employ masking and features within IDEAS software to accurately select the area of interest during image analysis (20). Our study describes procedures to accurately identify cellular phenotypes and quantify phagocytosis by cells from three very different aquatic animals.

In the present IFC study, we could successfully exclude dead cells and cell aggregates and could identify single leukocytes from Atlantic salmon HK based on bright field (BF) area and SSC intensity. We observed two distinct populations: cells located in the low BF area and low SSC intensity, and cells located in the high $\mathrm{BF}$ area and high SSC intensity. Our IFC results are in agreement with conventional FC data on HK leukocytes from salmon (21). A study on goldfish primary kidney macrophages 


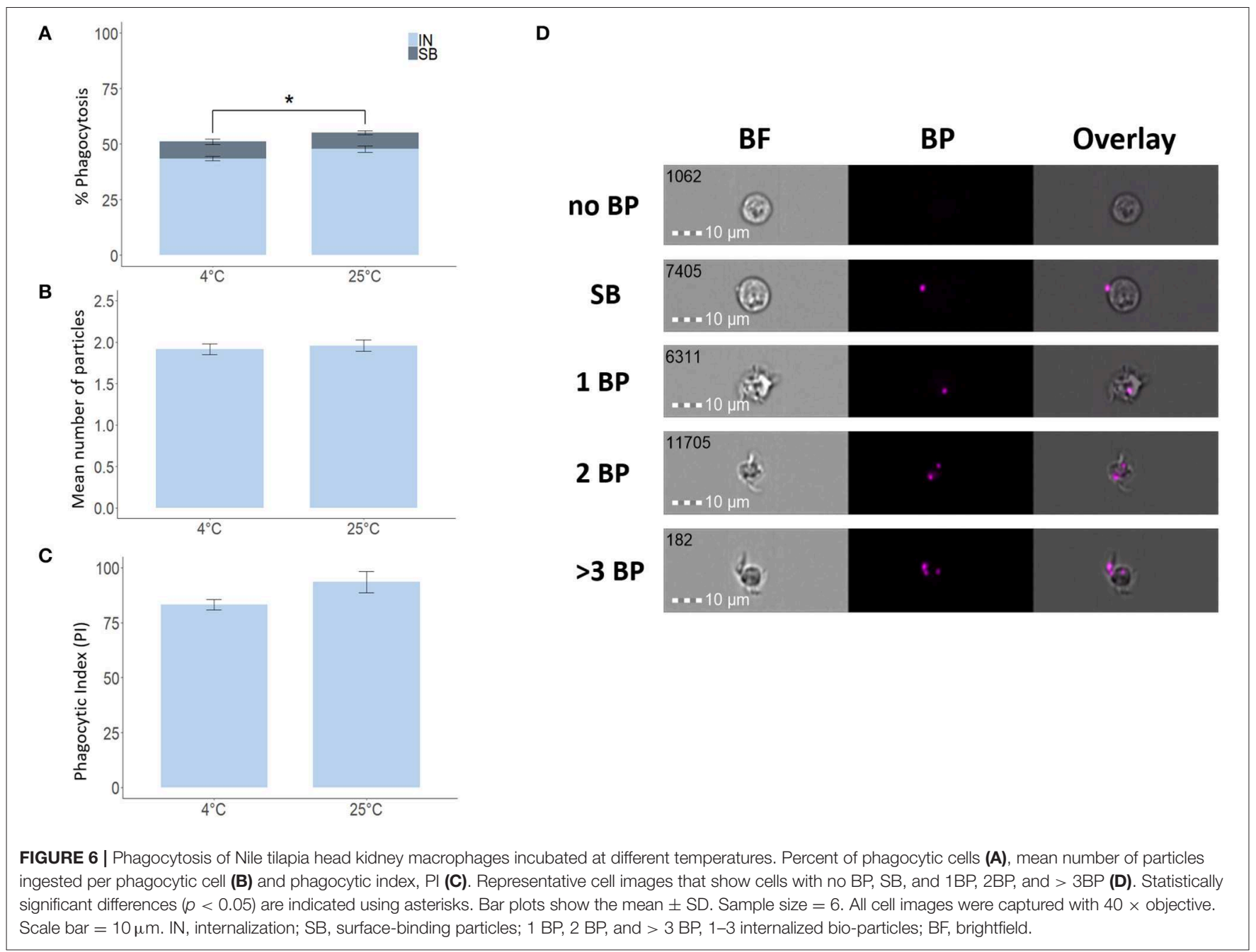

also compared IFC results with those from conventional FC data; both systems were used to identify cell sub-populations. Similar dot plots were generated for both flow cytometry systems, indicating that the replacement of forward scatter (FSC) which measures cell size in conventional FC by BF area in IFC (22) is a reliable approach, independent of fish species.

Interestingly, adherent cells from Atlantic salmon HK (R3, macrophage-like cells) were located in a higher BF area than R2 cells from the same organ (Figures 1D,E). The proportion of macrophage-like cells was approximately $45.2 \%$. The macrophage-like cells in the R3 region displayed a similar morphology to that of the adherent TO cells, a cell line originating from salmon HK leukocytes (23). Furthermore, in another study that employed conventional FC, salmon macrophage-like cells were presented in an FSC vs. SSC plot (24). Similar to our gating, the author gated three regions in the plot and assumed that the two higher FSC regions contained macrophage-like cells which was $\sim 56 \%$ out of the total number of cells.

After optimizing the method to distinguish between lymphocytes from monocytes/macrophages, magnetic cell sorting (MACS) was performed to sort target lymphocytes using an IgM-specific antibody. The purity of $\operatorname{IgM}^{+}$cells after MACS was $89.8 \%$ which is similar to $92 \%$ in a salmon study (25). MACS enabled us to ascertain the area of lymphocyte-like cells as defined/interpreted from the BF area vs. SSC intensity plots. The sorted salmon $\mathrm{IgM}^{+}$cells were located in the low BF area and low SSC intensity gate, confirming a close area match to that of the lymphocyte-like cells. Similarly, a previous study on trout HK confirmed lymphocyte localization (low FSC and low SSC) using conventional FC, based on $\mathrm{CD}^{+} \mathrm{T}$ cell markers (26). In addition, employing conventional $\mathrm{FC}$, percentage of $\mathrm{IgM}^{+}$ and $\mathrm{IgT}^{+} \mathrm{B}$ cells in salmon HK cells were determined by gating the same area (25). The gate areas in Figures 1, 2 confirm the presence of lymphocytes.

After confirming the identity of the B lymphocytes in the low BF area vs. low SSC intensity gate, we explored the phagocytosis of the adherent monocytes/macrophages HK fraction. Phagocytosis is an important initial immune response with final entry of antigens into the phagosomes/lysosomes that stimulates the production of reactive oxygen species (27). Phagocytic activity is influenced by many factors such as cell 


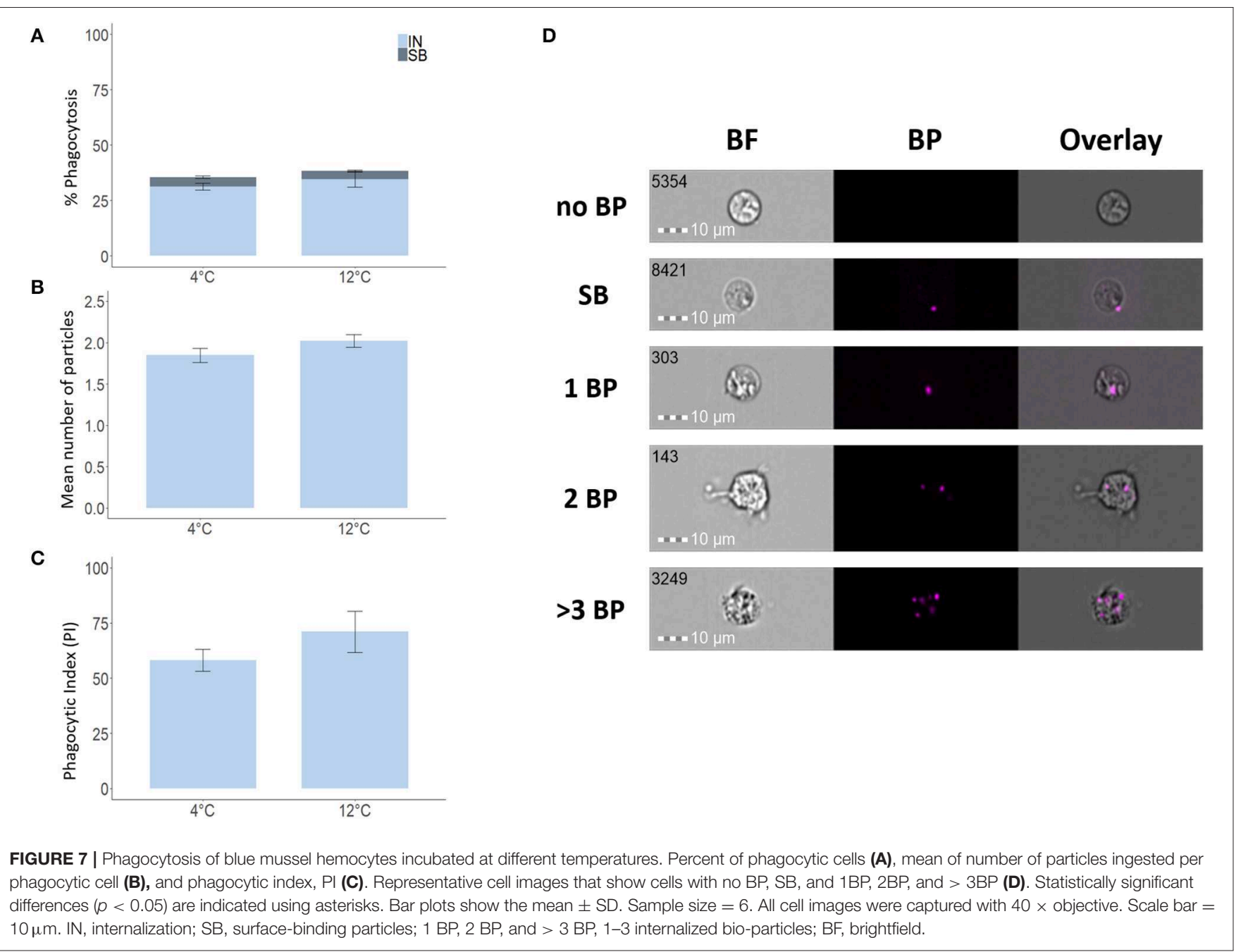

maturity, cytokine response, antigen presenting cell activation status (28) and the characteristics of phagocytosed antigens or particles (29). We explored the phagocytic activity of salmon HK cells using IFC, which allowed for not only quantification of the number of cells with internalized particles but also the localization of particles inside the cells. The IFC methods for assessing phagocytosis are complex, and researchers are yet to standardize them for different particle types. In the present study, we tested two different types of particles, nondegradable and degradable particles. This is the first IFC study that reports the use of microplastic as non-degradable particles and bio-particles from $E$. coli as degradable particles. Considering the growing debate on microplastic pollution of the marine ecosystem, studying phagocytosis of microplastics by immune cells from aquatic animals can be of particular interest from an environmental perspective. In our studies, with our sensitive IFC methodology, we could clearly detect microplastic particles engulfed by salmon macrophages, although only few particles were detected inside these cells. We, therefore, assume that these cell types can phagocytose microplastics as (foreign) particles. It should be pointed out that the salmon HK phagocytic cells were not able to uptake more microplastics; the reason could be that the cells can efficiently recognize microbe-derived particles (bio particle from E. coli) due to their natural antigenicity and phagocytose it more easily than an "unknown particle" such as the microplastic. Furthermore, the microplastic beads are not coated with any compound recognizable by the phagocytic cells, and they are larger compared to the bioparticles.

Compared to microplastic particles, the bio-particles are known to emit fluorescence within cells. However, this occurs only upon acidification, i.e., they emit fluorescence of a particular wavelength, depending on the $\mathrm{pH}$ level that the particle encounters. Hence, we suggest the use of fluorescent intensity feature rather than spot count feature to accurately assess the counts of degradable particles in phagocytes. Although a different feature was used to count the number of particles per phagocytic cell, a publication (12) has reported an IFC method for counting internalized fluorescent-labeled bacteria. The author succeeded in distinguishing between cells with high bright detail similarity score and those with low bright detail similarity score; the former one had internalized particles while other cells had external particles. Although the method of Smirnov et al. (12) gives 
information on the overall degree of phagocytosis in phagocytic cells, it cannot accurately count the internalized particles. Thus, the bright detail similarity score and fluorescent intensity feature are effective in detecting and counting (as in this report) the mean number of internalized particles per phagocytic cell.

Although we did not perform a direct comparison between IFC and conventional FC, from our results we understand that false events such as auto-fluorescence and aggregated particles can be misinterpreted in the case of conventional FC. Pixel and intensity features were adjusted carefully in the present study to exclude the false-positive events. Caution should be exercised when gating phagocytic cells using these features because in IFC, cell size is measured based on pixels, and the sensitivity of the measurement is dependent on the cell size (19). Thus, in order to include the region of interest for analysis, the mask that identifies the intracellular compartment has to be adjusted for different types of cells and particles.

After standardizing the protocols for monocytes/macrophage phagocytosis, we optimized the methods for measuring phagocytosis, using degradable bio-particles, by cells from three very different aquatic animals-two fishes, Atlantic salmon and Nile tilapia and a mollusc, blue musselto evaluate the effect of incubation temperature on their phagocytic abilities and capacities. Our results indicated that phagocytosis of cells from the fishes can be affected by the incubation temperature. Although not directly comparable, phagocytosis of human leukocytes was reduced at higher and lower temperature compared to the normal host temperature range (30). Interestingly, the phagocytosis by hemocytes from blue mussel, a eurythermal species that can tolerate a broad temperature range from -1 to $20^{\circ} \mathrm{C}(31,32)$, was not affected by incubation temperature.

In summary, IFC was used to study phagocytosis in fish and mussel cells. We were able to identify cell populations and determine the phagocytosis of different kinds of particles by quantifying the number of internalized particles and detecting the localization of particles in the phagocytes. This study provides important information about how IFC can be used in the field of fish immunology and ecotoxicology. Furthermore, the

\section{REFERENCES}

1. Görgens A, Bremer M, Ferrer-Tur R, Murke F, Tertel T, Horn PA, et al. Optimisation of imaging flow cytometry for the analysis of single extracellular vesicles by using fluorescence-tagged vesicles as biological reference material. J Extracell Vesicles. (2019) 8:1587567. doi: 10.1080/20013078.2019.15 87567

2. Barteneva NS, Fasler-Kan E, Vorobjev IA. Imaging flow cytometry: coping with heterogeneity in biological systems. J Histochem Cytochem. (2012) 60:723-33. doi: 10.1369/0022155412453052

3. Hulspas R, O'gorman MR, Wood BL, Gratama JW, Sutherland DR. Considerations for the control of background fluorescence in clinical flow cytometry. Cytom B Clin Cytom. (2009) 76:355-64. doi: 10.1002/cyto.b.20485

4. Van Beers EJ, Samsel L, Mendelsohn L, Saiyed R, Fertrin KY, Brantner CA, et al. Imaging flow cytometry for automated detection of hypoxia-induced erythrocyte shape change in sickle cell disease. Am J Hematol. (2014) 89:598603. doi: 10.1002/ajh.23699 procedures described in this report may have wider application in aquatic sciences, to unravel the effects of microplastic-ingestion by living organisms in the oceans.

\section{DATA AVAILABILITY STATEMENT}

All datasets generated for this study are included in the article/supplementary material.

\section{ETHICS STATEMENT}

The animal study was reviewed and approved by National Animal Research Authority in Norway (Mattilsynet).

\section{AUTHOR CONTRIBUTIONS}

YP and VK conceived and designed the study. YP and IA-G performed the experiments. YP analyzed the data and wrote the first draft of the manuscript while IA-G wrote a section of it. ST, GW and DB provided suggestions to improve the IFC protocols. YP, IA-G, ST, GW, DB, PO, and VK read, revised, and approved the manuscript for submission.

\section{FUNDING}

This study was supported by the INFISH project (272004) funded by Regional Forskningsfond Nord-Norge (RFF Nord-Norge). YP was financially supported by Korean Government ScholarshipNational Institute for International Education, South Korea.

\section{ACKNOWLEDGMENTS}

The support of the staff at the Research Station, Nord University, Norway is acknowledged. YP is grateful to the members of the Cell Biology and Immunology Group, Wageningen University, the Netherlands for teaching him the principles of flow cytometry. Bisa Saraswathy is thanked for her support in data analysis, helpful discussion, and manuscript preparation.
5. Ofir-Birin Y, Abou Karam P, Rudik A, Giladi T, Porat Z, Regev-Rudzki N. Monitoring extracellular vesicle cargo active uptake by imaging flow cytometry. Front Immunol. (2018) 9:1011. doi: 10.3389/fimmu.2018.01011

6. Piancone F, Saresella M, Marventano I, La Rosa F, Santangelo MA, Caputo D, et al. Monosodium urate crystals activate the inflammasome in primary progressive multiple sclerosis. Front Immunol. (2018) 9:983. doi: $10.3389 /$ fimmu.2018.00983

7. Jenner D, Ducker C, Clark G, Prior J, Rowland CA. Using multispectral imaging flow cytometry to assess an in vitro intracellular Burkholderia thailandensis infection model. Cytom A. (2016) 89:328-37. doi: 10.1002/cyto.a.22809

8. Rieger AM, Konowalchuk JD, Grayfer L, Katzenback BA, Havixbeck JJ, Kiemele MD, et al. Fish and mammalian phagocytes differentially regulate pro-inflammatory and homeostatic responses in vivo. PLoS ONE. (2012) 7:e47070. doi: 10.1371/journal.pone.0047070

9. Rességuier J, Delaune E, Coolen A-L, Levraud J-P, Boudinot P, Le Guellec $\mathrm{D}$, et al. Specific and efficient uptake of surfactant-free poly (lactic acid) 
nanovaccine vehicles by mucosal dendritic cells in adult zebrafish after bath immersion. Front Immunol. (2017) 8:190. doi: 10.3389/fimmu.2017.00190

10. Parra D, Rieger AM, Li J, Zhang YA, Randall LM, Hunter CA, et al. Pivotal advance: peritoneal cavity B-1 B cells have phagocytic and microbicidal capacities and present phagocytosed antigen to CD4+ T cells. J Leukocyte Biol. (2012) 91:525-36. doi: 10.1189/jlb.0711372

11. Phanse Y, Ramer-Tait AE, Friend SL, Carrillo-Conde B, Lueth P, Oster CJ, et al. Analyzing cellular internalization of nanoparticles and bacteria by multi-spectral imaging flow cytometry. J Visual Exp. (2012) 64:e3884. doi: $10.3791 / 3884$

12. Smirnov A, Solga MD, Lannigan J, Criss AK. An improved method for differentiating cell-bound from internalized particles by imaging flow cytometry. J Immunol Methods. (2015) 423:60-9. doi: 10.1016/j.jim.2015.04.028

13. Paulsen SM, Engstad RE, Robertsen B. Enhanced lysozyme production in Atlantic salmon (Salmo salar L.) macrophages treated with yeast $\beta$-glucan and bacterial lipopolysaccharide. Fish Shellfish Immunol. (2001) 11:23-37. doi: 10.1006/fsim.2000.0291

14. Pirarat N, Pinpimai K, Endo M, Katagiri T, Ponpornpisit A, Chansue N, et al. Modulation of intestinal morphology and immunity in Nile tilapia (Oreochromis niloticus) by Lactobacillus rhamnosus GG. Res Vet Sci. (2011) 91:e92-7. doi: 10.1016/j.rvsc.2011.02.014

15. Wen C-M. Development and characterization of a cell line from tilapia head kidney with melanomacrophage characteristics. Fish Shellfish Immunol. (2016) 49:442-9. doi: 10.1016/j.fsi.2016.01.013

16. Antoun SW. Mussel (Mytilus edulis) hemocytes for in vitro testing (dissertation/master's thesis). University of Oslo, Oslo, Norway (2011).

17. Barbuddhe SB, Malik SVS, Gupta LK. Effect of in vitro monocyte activation by Listeria Monocytogenes antigens on phagocytosis and production of reactive oxygen and nitrogen radicals in bovines. Vet Immunol Immunopathol. (1998) 64:149-59. doi: 10.1016/S0165-2427(98)00129-9

18. Fuentes A-L, Millis L, Vapenik J, Sigola L. Lipopolysaccharide-mediated enhancement of zymosan phagocytosis by RAW 264.7 macrophages is independent of opsonins, laminarin, mannan, and complement receptor 3. J Surg Res. (2014) 189:304-12. doi: 10.1016/j.jss.2014. 03.024

19. Basiji DA. Principles of Amnis Imaging Flow Cytometry in Imaging Flow Cytometry. Berlin: Springer (2016) 13-21. doi: 10.1007/978-1-4939-3302-0_2

20. Grimwade LF, Fuller KA, Erber WN. Applications of imaging flow cytometry in the diagnostic assessment of acute leukaemia. Methods. (2017) 112:39-45. doi: 10.1016/j.ymeth.2016.06.023

21. Kalgraff CA, Wergeland HI, Pettersen EF. Flow cytometry assays of respiratory burst in Atlantic salmon (Salmo salar L.) and in Atlantic cod (Gadus morhua L.) leucocytes. Fish Shellfish Immunol. (2011)31:381-8. doi: 10.1016/j.fsi.2011.05.028

22. Rieger AM, Hall BE, Barreda DR. Macrophage activation differentially modulates particle binding, phagocytosis and downstream antimicrobial mechanisms. Dev Compar Immunol. (2010) 34:1144-59. doi: 10.1016/j.dci.2010.06.006
23. Pettersen EF, Ingerslev H-C, Stavang V, Egenberg M, Wergeland HI. A highly phagocytic cell line TO from Atlantic salmon is CD83 positive and M-CSFR negative, indicating a dendritic-like cell type. Fish Shellfish Immunol. (2008) 25:809-19. doi: 10.1016/j.fsi.2008.08.014

24. Ulvestad JS. Studies on the stimulation of Atlantic salmon macrophage-like cells with emphasis on respiratory burst (dissertation/master's thesis). UiT The Arctic University of Norway, Tromsø, Norway (2017).

25. Jenberie S, Thim HL, Sunyer JO, Skjødt K, Jensen I, Jørgensen JB. Profiling Atlantic salmon B cell populations: CpG-mediated TLR-ligation enhances IgM secretion and modulates immune gene expression. Sci Rep. (2018) 8:3565. doi: 10.1038/s41598-018-21895-9

26. Maisey K, Montero R, Corripio-Miyar Y, Toro-Ascuy D, Valenzuela B, ReyesCerpa S, et al. Isolation and characterization of salmonid CD4+ T cells. J Immunol. (2016) 196:4150-63. doi: 10.4049/jimmunol.1500439

27. Gartlan KH, Krashias G, Wegmann F, Hillson WR, Scherer EM, Greenberg $\mathrm{PD}$, et al. Sterile inflammation induced by Carbopol elicits robust adaptive immune responses in the absence of pathogen-associated molecular patterns. Vaccine. (2016) 34:2188-96. doi: 10.1016/j.vaccine.2016.03.025

28. Gordon S. Phagocytosis: an immunobiologic process. Immunity. (2016) 44:463-75. doi: 10.1016/j.immuni.2016.02.026

29. Underhill DM, Goodridge HS. Information processing during phagocytosis. Nat Rev Immunol. (2012) 12:492. doi: 10.1038/nri3244

30. Peterson P, Verhoef J, Quie P. Influence of temperature on opsonization and phagocytosis of staphylococci. Infect Immun. (1977) 15:175-9. doi: 10.1128/IAI.15.1.175-179.1977

31. Hiscock K, Tyler-Walters H. Assessing the sensitivity of seabed species and biotopes-the Marine Life Information Network (MarLIN). Hydrobiologia. (2006) 555:309-20. doi: 10.1007/s10750-0051127-z

32. Thyrring J, Rysgaard S, Blicher ME, Sejr MK. Metabolic cold adaptation and aerobic performance of blue mussels (Mytilus edulis) along a temperature gradient into the high Arctic region. Marine Biol. (2015) 162:235-43. doi: $10.1007 / \mathrm{s} 00227-014-2575-7$

Conflict of Interest: ST is an employee of Luminex B.V., which is a subsidiary of Luminex Corporation. Luminex Corporation is the manufacturer of the ImageStream ${ }^{\circledR X}$ Mk II Imaging Flow Cytometer.

The remaining authors declare that the research was conducted in the absence of any commercial or financial relationships that could be construed as a potential conflict of interest.

Copyright (c) 2020 Park, Abihssira-García, Thalmann, Wiegertjes, Barreda, Olsvik and Kiron. This is an open-access article distributed under the terms of the Creative Commons Attribution License (CC BY). The use, distribution or reproduction in other forums is permitted, provided the original author(s) and the copyright owner(s) are credited and that the original publication in this journal is cited, in accordance with accepted academic practice. No use, distribution or reproduction is permitted which does not comply with these terms. 